\title{
8
}
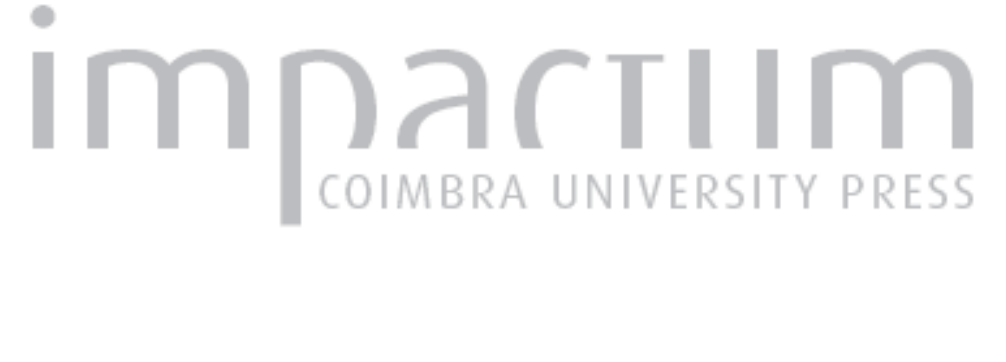

Impactos das chuvas na cidade de Fortaleza no triênio 2013, 2014 e 2015

\author{
Autor(es): $\quad$ Lima, João Sérgio Queiroz; Santos, Jader de Oliveira; Zanella, Maria
}

Publicado por: Imprensa da Universidade de Coimbra

URL

persistente:

URI:http://hdl.handle.net/10316.2/43268

DOI:

DOI:https://doi.org/10.14195/1647-7723_25-1_1

Accessed : $\quad$ 26-Apr-2023 12:58:46

A navegação consulta e descarregamento dos títulos inseridos nas Bibliotecas Digitais UC Digitalis, UC Pombalina e UC Impactum, pressupõem a aceitação plena e sem reservas dos Termos e Condições de Uso destas Bibliotecas Digitais, disponíveis em https://digitalis.uc.pt/pt-pt/termos.

Conforme exposto nos referidos Termos e Condições de Uso, o descarregamento de títulos de acesso restrito requer uma licença válida de autorização devendo o utilizador aceder ao(s) documento(s) a partir de um endereço de IP da instituição detentora da supramencionada licença.

Ao utilizador é apenas permitido o descarregamento para uso pessoal, pelo que o emprego do(s) título(s) descarregado(s) para outro fim, designadamente comercial, carece de autorização do respetivo autor ou editor da obra.

Na medida em que todas as obras da UC Digitalis se encontram protegidas pelo Código do Direito de Autor e Direitos Conexos e demais legislação aplicável, toda a cópia, parcial ou total, deste documento, nos casos em que é legalmente admitida, deverá conter ou fazer-se acompanhar por este aviso.

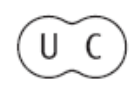


territorium/25w|.

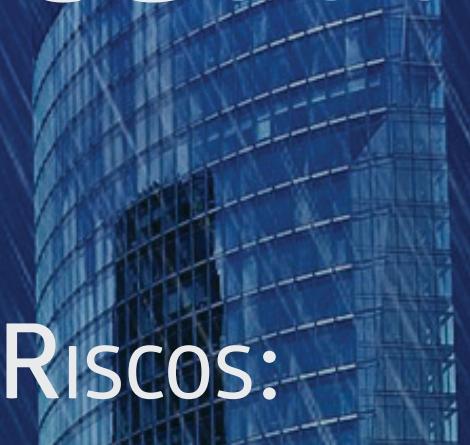

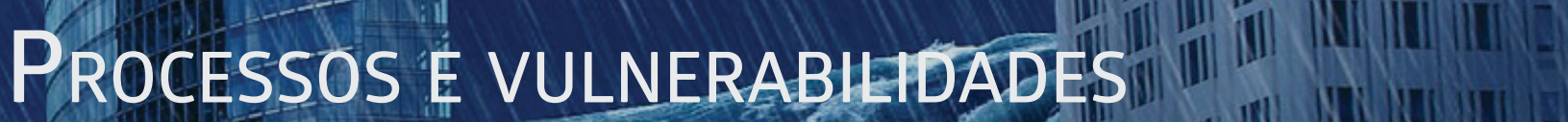

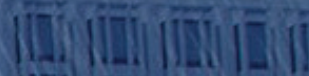
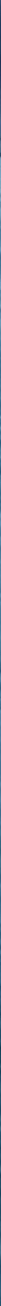

Imprensa da Universidade de Coimbra

Associação Portuguesa de Riscos, Prevenção e Segurança

2018 


\section{IMPACTOS DAS CHUVAS NA CIDADE DE FORTALEZA NO TRIÊNIO 2013, 2014 E 2015*}

IMPACT OF THE RAINS ON THE CITY OF FORTALEZA IN THE YEARS 2013, 2014 AND 2015

João Sérgio Queiroz de Lima

Departamento de Geografia, Universidade Federal do Ceará-UFC (Brasil) joaosergi01980@gmail.com

Jader de Oliveira Santos

Departamento de Geografia, Universidade Federal do Ceará-UFC (Brasil) jadersantos@gmail.com

Maria Elisa Zanella

Departamento de Geografia, Universidade Federal do Ceará-UFC (Brasil) elisazv@terra.com.br

\section{RESUMO}

O presente artigo objetiva avaliar os impactos das chuvas na Cidade de Fortaleza, quinta metrópole do Brasil, entre os anos de 2013 e 2015. Utiliza-se o método Sistema Clima Urbano para investigação ambiental integrada, com ênfase na climatologia geográfica. O sítio urbano de Fortaleza apresenta diversos ambientes suscetíveis a eventos deflagrados pelas chuvas. Alagamentos e inundações em planícies fluviais, lacustres e flúviomarinhas e movimentos de massa em encostas íngremes de dunas afetam o espaço urbano, além de ressacas do mar na zona costeira. Eventos pluviais acima de $30 \mathrm{~mm} /$ dia causam problemas generalizados na cidade, com os mais graves sendo os eventos extremos, acima de $100 \mathrm{~mm} /$ dia. Os mais sérios danos incidiram sobre a mobilidade e no uso residencial em todas as regiões do município. Interpreta-se que a sociedade local não apresenta preparo suficiente para lidar com os problemas ambientais detectados, resultado da ocupação inadequada dos ambientes naturais, múltiplas deficiências das infraestruturas urbanas e baixo nível de organização comunitária e das instituições públicas frente às situações de crise.

Palavras-chave: Chuvas, Cidade de Fortaleza, problemas ambientais.

\section{ABSTRACT}

This article aims to assess the impact of the rains in Fortaleza city, the fifth metropolis in Brazil, between 2013 and 2015. To achieve an integrated environmental investigation, the Urban Climate System method was adopted, with emphasis on geographic climatology. The urban site of Fortaleza presents several environments prone to events triggered by rain. Inundation and flooding around rivers, lakes and estuaries and landslides near dune slopes affect the urban space, besides storm waves impacting on the coastal zone. Rainfall events above $30 \mathrm{~mm} /$ day cause widespread problems in the city, the most severe problems being seen during extreme events, above $100 \mathrm{~mm} / \mathrm{day}$. The most severe impacts occurred on mobility and residences all over the city. In conclusion, local society in not prepared to cope with the environmental problems discussed in this work, as a result of the inappropriate occupation of the environment, several deficiencies of urban infrastructure and low level of organization of community and public institutions to face crisis situations.

Keywords: Rains, city of Fortaleza, environmental problems.

\footnotetext{
* O texto deste artigo foi submetido em 10-06-2016, sujeito a revisão por pares a 02-09-2016 e aceite para publicação em 17-05-2017.

Este artigo é parte integrante da Revista Territorium, n. ${ }^{\circ} 25$ (I), 2018, ${ }^{\circ} \mathrm{RIscos}$, ISSN: 0872-8941.
} 
Introdução

Os eventos climáticos têm provocado, historicamente, impactos socioeconômicos em todo o Mundo, sobretudo nos países e regiões subdesenvolvidos, mais dependentes economicamente, cujas condições precárias de organização socioespacial tornam grupos sociais altamente vulneráveis aos efeitos adversos da dinâmica natural.

Nesse contexto, situações de desastre ambiental são produzidas quando os fenômenos atmosféricos impactam e desorganizam a sociedade, demonstrando a ocorrência de eventos extremos, não necessariamente pelos desvios do padrão normal de ocorrência (excesso ou escassez), mas pelos danos provocados.

No Brasil, as precipitações pluviais concentradas e seus efeitos nos fenômenos hidrológicos e geomorfológicos de elevada intensidade são os eventos mais impactantes nas cidades, sobretudo em espaços cuja organização territorial é inadequada em termos de infraestrutura e quanto ao uso e ocupação frente às características naturais.

No país, esses eventos climáticos atingem os espaços urbanos de forma irregular e relativamente imprevisível, como bem afirma C. A. F. Monteiro (2011, p.56): “Quase todas as nossas áreas metropolitanas têm problemas anuais de inundações do espaço urbano em diferentes graus de intensidade e, de quando em quando, são teatros de calamidades".

Com base nessas considerações e a partir da realidade observada nos principais centros urbanos brasileiros, evidencia-se que a gestão pública tem se mostrado ineficiente no tratamento dos problemas relacionados aos impactos derivados dos eventos pluviais concentrados.

$\mathrm{Na}$ Cidade de Fortaleza os problemas deflagrados pelas chuvas são evidenciados historicamente, a cada período chuvoso. Os mais significativos efeitos adversos são produzidos essencialmente pela vulnerabilidade decorrente da deficiência da infraestrutura de saneamento e drenagem e pela ocupação inadequada de ambientes naturais suscetíveis à ocorrência de eventos como inundações, alagamentos e movimentos de massa. Nesse ínterim, grande contingente populacional está vulnerável aos impactos hidrometeóricos, com a geração de problemas socioambientais diversos.

O presente artigo objetiva avaliar os impactos urbanos deflagrados por eventos naturais hidroclimáticos no território da Cidade de Fortaleza, utilizando período amostral entre 2013 e 2015. Aavaliação aborda os impactos hidrometeóricos noticiados nos meios de comunicação, representados pelos portais de notícias dos jornais locais disponíveis na internet, e a correspondência com os boletins de ocorrência dos órgãos públicos municipais de defesa civil e de gerenciamento de trânsito.
O referencial teórico-metodológico utilizado alude ao Sistema Clima Urbano-SCU proposto por C. A. F. Monteiro (1976). Os eventos de precipitação concentrados, deflagradores dos impactos, foram estudados e classificados em função dos totais pluviométricos (em mm), distribuição espacial e ocorrência de eventos extremos. Essa abordagem possibilita um melhor entendimento da dinâmica e espacialização dos problemas de ocupação do sítio urbano, das deficiências da infraestrutura e despreparo da sociedade no enfrentamento de situações críticas, deflagradas por eventos naturais climáticos e suas repercussões hidrológicas e geomorfológicas.

A série temporal amostral utilizada, 2013 a 2015, exemplifica o histórico de problemas na cidade através da ocorrência mais atual dos eventos de chuva. Nesse período, o advento da mídia eletrônica permitiu maior atenção, abrangência e detalhamento das informações pela imprensa local, com ampla disponibilidade de dados sobre o tema em pauta, seguindo periodicidade cotidiana.

Esse período também marca o início do monitoramento dos impactos causados pelas chuvas, em escala municipal e cotidiana, realizado no âmbito do Grupo de Pesquisa sobre Fragilidades e Riscos Ambientais Urbanos, integrante do Laboratório de Geoprocessamento (LABOCART) do Departamento de Geografia da Universidade Federal do Ceará (UFC).

O tipo de abordagem empregado se diferencia das tradicionalmente utilizadas no tratamento dos impactos hidrometeóricos em ambiente urbanos. Nesse contexto, são levantados primeiramente os relatos de problemas ocorridos em todo o território da cidade, através das informações disponíveis pela mídia local, para subsequentemente se investigar a influência dos eventos naturais na geração e distribuição espacial dos impactos, analisando-se os dados pluviométricos e as características geoambientais do sítio urbano.

Os jornais locais dispõem atualmente de informações de abrangência espacial e temporal suficiente para abordagem integral do território municipal com registros diários. Esse avanço facilitou a obtenção de dados de difícil monitoramento em tempo real em campo. Na busca da correspondência das informações midiáticas com os dados oficiais foram sistematizados e integrados os registros dos órgãos públicos quanto ao atendimento emergencial nos dias com impactos das chuvas observados. Para tanto, foram pesquisados e avaliados os boletins de ocorrência da Coordenadoria Municipal de Defesa Civil (COMDECFor) e Autarquia Municipal de Trânsito e Cidadania (AMC), integrantes da estrutura administrativa da Prefeitura Municipal de Fortaleza (PMF).

Os boletins de ocorrência desses órgãos públicos são restritos e de uso interno, contudo, foi possível o acesso 
através de pesquisa in loco. A COMDEC-For disponibilizou informações sobre os atendimentos de emergência nas áreas residenciais atingidas pelas chuvas, com a materialização de danos, como desabamento de imóveis e pessoas desabrigadas. A AMC listou as principais vias públicas com interrupções parciais ou totais no trânsito de veículos, assim como problemas técnicos em semáforos e placas de sinalização.

\section{Área de estudo}

A Cidade de Fortaleza localiza-se a $3^{\circ} 45^{\prime} 47^{\prime \prime}$ de latitude sul e a $38^{\circ} 32^{\prime} 35^{\prime \prime}$ de longitude oeste, ocupando área territorial de $314,9 \mathrm{Km}^{2}$, na porção norte-nordeste do Estado do Ceará, Região Nordeste do Brasil (fig. 1). Como principal centro urbano cearense, concentrou o maior contingente populacional do Estado em 2010, ocupando status de metrópole regional e quinto maior centro urbano do país, com 2.452.185 habitantes (BRASIL, 2013).
O sítio urbano de Fortaleza é composto por um conjunto de ambientes naturais predominantemente litorâneos e pré-litorâneos fortemente alterados e densamente ocupados, caracterizados por elevada fragilidade ambiental, conforme avaliam M. J. N. Souza et al. (2009), J. O. Santos (2011 e 2015) e J. O. Santos e J. L. S. Ross (2012). Essa condição de fragilidade ambiental indica forte suscetibilidade a eventos naturais intensos e extremos.

Entre esses eventos são recorrentes as inundações, suscetíveis principalmente nas planícies fluviais, flúviolacustres e flúviomarinhas, localizadas em classes altimétricas inferiores a 5 metros de altitude. As áreas de inundação sazonal localizadas nessas classes são suscetíveis aos alagamentos. Os movimentos de massa são altamente suscetíveis nas encostas das dunas em vertentes superiores a 50 metros de altitude, embora possam também ocorrer em vertentes

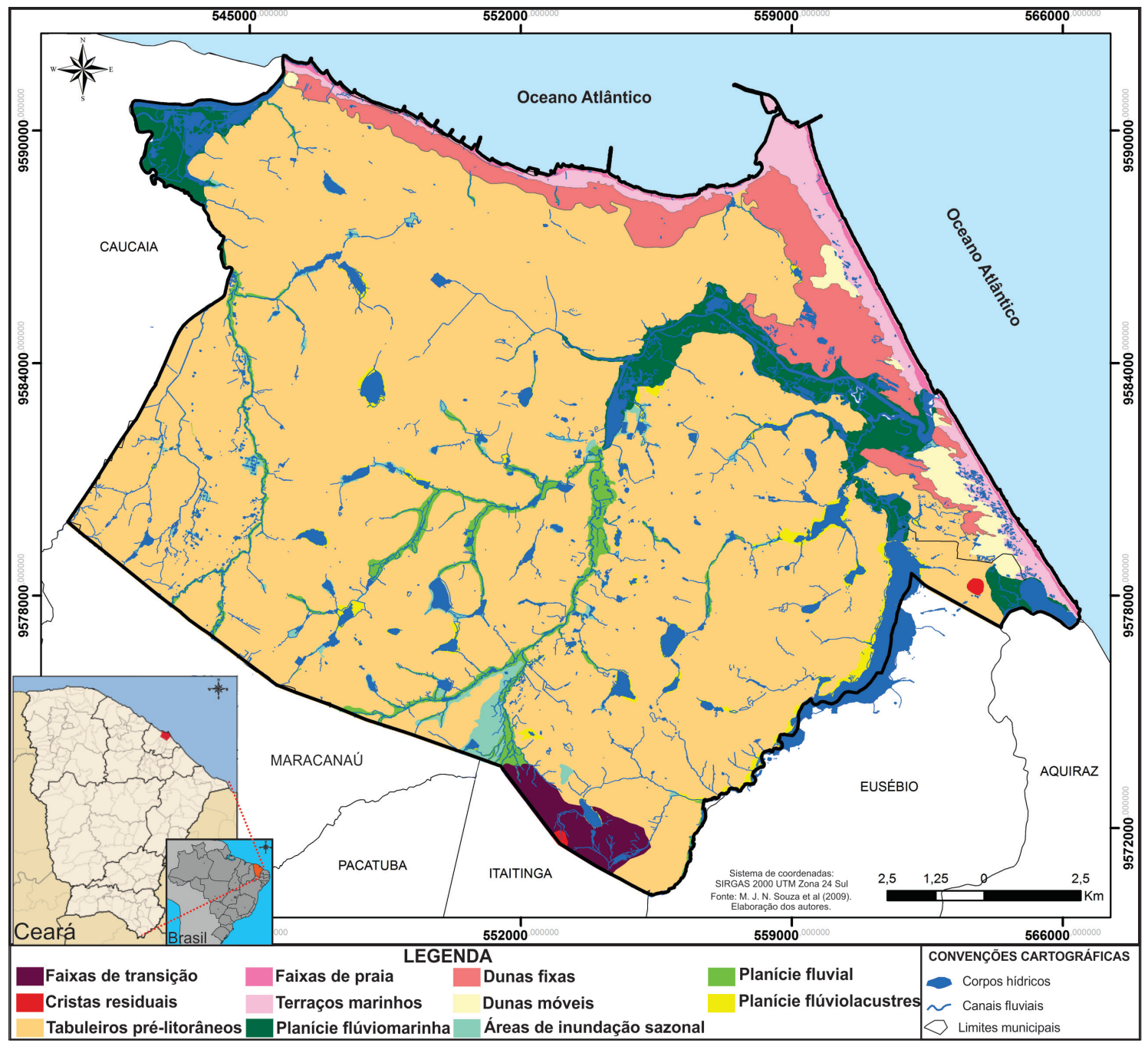

Fig. 1 - Cidade de Fortaleza - localização e sítio urbano (Fonte: adaptado de M. J. N Souza et al., 2009)

Fig. 1 - City of Fortaleza - location and urban site (Source: adapted from M. J. N Souza et al., 2009). 
entre 30 e 50 metros (fig. 2). Em todas as situações o agente natural indutor fundamental corresponde às manifestações climáticas.

Nesse contexto, são considerados como ambientes de elevada fragilidade ambiental as faixas de praia, encostas de dunas móveis e de dunas fixas fortemente alteradas, planícies flúviomarinhas, fluviais, flúviolacustres e lacustres. Os setores mais abrigados das inundações nessas planícies e as áreas de inundação sazonal são ambientes de fragilidade ambiental média. As áreas consideradas com fragilidade ambiental baixa são os tabuleiros pré-litorâneos e a faixa de transição entre os tabuleiros e a superfície sertaneja. A suscetibilidade natural desses ambientes à ocorrência de eventos intensos e extremos é potencializada pelas características climáticas e principais sistemas atmosféricos atuantes no sítio urbano em questão, submetido ao clima regional atuante em todo Nordeste brasileiro.

As chuvas na região Nordeste do Brasil funcionam de acordo com atuação da Zona de Convergência
Intertropical (ZCIT); dos Vórtices Ciclônicos de Altos Níveis (VCAN); das Linhas de Instabilidade (LI); dos Complexos Convectivos de Mesoescala (CCM); das Ondas de leste $(\mathrm{OL})$; e dos efeitos das brisas marítimas e terrestres. A variabilidade interanual da chuva tem como mecanismos mais importantes os fenômenos El Niño-Oscilação Sul (ENOS) e a temperatura da superfície do mar (TSM) na bacia do Oceano Atlântico, conforme análises de A. G. Ferreira e N .G. S. Mello (2005); M. E. Zanella, M. C. L. Sales e N. J. A. Abreu (2009); J. B. Magalhães e M. E. Zanella (2011), J. B. Monteiro e M. E. Zanella (2013).

A ZCIT é o sistema atmosférico de maior importância no clima da Cidade de Fortaleza, atuando nos meses de fevereiro, março, abril e maio. Os Vórtices Ciclônicos de Altos Níveis (VCAN) atuam na pré-estação chuvosa (janeiro, fevereiro e março). As Linhas de Instabilidade atuam em fevereiro e março. Os Complexos Convectivos de Mesoescala atuam no período chuvoso, de forma isolada, podendo ocasionar chuvas extremas. As Ondas de Leste atuam nos meses de junho e julho. Com menor

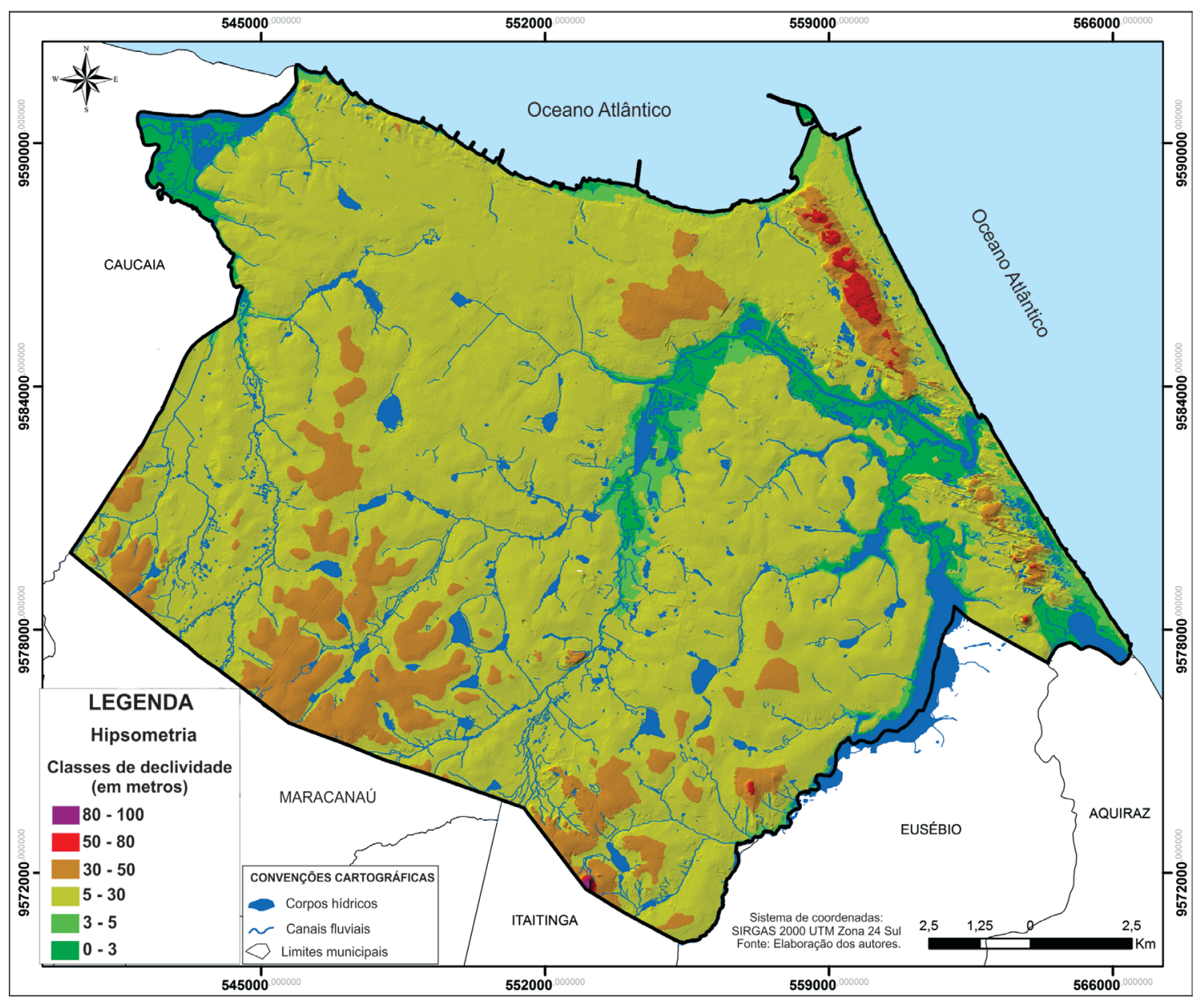

Fig. 2 - Cidade de Fortaleza - hipsometria.

Fig. 2 - City of Fortaleza - hypsometry. 
importância, os sistemas de Brisas ocasionam chuvas na área costeira. Esses sistemas determinam as condições espaço-temporais de precipitação pluviométrica e outros elementos climáticos importantes para a qualidade ambiental urbana.

No sítio urbano de Fortaleza a ocupação inadequada de ambientes com elevada fragilidade ambiental produz condições favoráveis à deflagração de situações críticas decorrentes de eventos naturais, com sérios efeitos adversos quando atingem áreas marcadas pela precariedade urbana e vulnerabilidade social. Nesse ínterim, os processos hidroclimáticos assumem importância fundamental como principais causadores dos problemas ambientais urbanos.

Impactos hidrometeóricos no contexto do Sistema Clima Urbano

Nas abordagens pioneiras sobre o Clima Urbano, apresentadas por T. J. Chandler (1976), H. E. Landsberg (1976), T. R. Oke (1984), R. Taesler (1986), entre outros, são analisadas com maior ênfase as influências das características físicas da urbanização na baixa atmosfera, cujos efeitos são capazes de provocar mudanças climáticas locais, alterando parâmetros meteorológicos, como temperatura, qualidade do ar e umidade.

Esses primeiros ensaios teóricos suscitaram desenvolvimentos metodológicos que permitissem aplicações práticas em estudos mais detalhados sobre objetos específicos, sobretudo no âmbito da climatologia geográfica. Dessa forma, o Sistema Clima Urbano se apresenta como um referencial com potencial adequado para a abordagem dos impactos causados pelas chuvas na organização territorial urbana.

O Sistema Clima Urbano-SCU integra um referencial teórico e metodológico aplicado à análise do clima da cidade, no âmbito dos estudos ambientais integrados em Geografia. Segundo C. A .F. Monteiro (2011) as cidades são resultantes das derivações ambientais das condições naturais originais por sítios produzidos por acréscimos, eliminações, substituições e alterações realizadas pela organização da sociedade aliada à própria dinâmica da população. Nesse contexto o autor define o clima urbano como um sistema composto de múltiplas variáveis que integra o clima atuante em determinado território e sua urbanização, resultante da integração espacialdinâmica entre o fato natural climático e o fato social urbano, independentemente da escala da cidade, grau de urbanização ou complexidade natural.

A. M. P. M. Brandão (2001) e F. Mendonça (2011) destacam que o sistema climático urbano integra a importância do processo de urbanização na derivação do clima da cidade. O clima urbano, parte fundamental do estudo da cidade, aparece como recorte fundamental à compreensão dos problemas urbanos e à sua gestão no presente e no futuro.

No Sistema Clima Urbano-SCU o intuito fundamental é a compreensão do comportamento climático específico da cidade. A atmosfera como operadora do sistema, integrando-se de forma sistêmica à dinâmica natural aos processos da urbanização, independentemente da categoria dimensional e populacional da cidade, tendo sempre a sociedade como o referencial dos fatos geográficos. Os canais de percepção sobre o clima urbano são meios de categorizar como as manifestações dos eventos climáticos impactam os grupos sociais urbanos.

O canal mais interessante à pesquisa refere-se aos meteoros de impacto, como produtores de perturbações e desorganização na cidade. Esse canal é abordado no subsistema climático urbano hidrometeórico (integrado indissociavelmente aos demais subsistemas: termodinâmico e físico-químico). Os meteoros de impacto geram como produtos ataques à integridade urbana. Como exemplos, nos climas tropicais, manifestam-se principalmente através de agentes hídricos, como fortes chuvas (C. A. F. Monteiro, 1990).

As manifestações meteóricas de impacto são insumos energéticos e materiais atmosféricos de origem natural. De diferentes amplitudes na escala global, variam de acordo com os mecanismos atmosféricos influentes no clima regional das cidades. Para os estudos do clima urbano no Brasil as precipitações pluviais são as manifestações mais interessantes nesse contexto.

Os meteoros de impacto têm caráter perturbador, com potencial de causar situações de desastres ambientais em função dos ataques à integridade das cidades (artefato físico) e desorganização dos processos socioeconômicos urbanos.

Segundo C. A. F. Monteiro (2011) os insumos meteóricos de impacto, como as chuvas, são intimamente relacionados à drenagem, escoamento superficial e fluvial. Essa relação expressa a integração sistêmica entre o clima regional e o ambiente natural terrestre considerado como sítio urbano, núcleo do sistema. Quando resultam de eventos extremos, em função das disritmias ou desvios dos padrões habituais do ritmo de sucessão dos estados atmosféricos, os impactos hidrometeóricos podem assumir proporções catastróficas.

Os eventos pluviais, na perspectiva dos impactos hidrometeóricos, podem ser classificados de acordo com vários parâmetros, selecionados em função dos objetivos da pesquisa. Os mais comuns, por exemplo, são intensidade, duração e frequência. No presente estudo foram adotados os totais pluviométricos, a abrangência espacial e extremidade dos eventos. Os valores considerados extremos, tanto negativos como positivos, são índices de referência para avaliação dos impactos potenciais ao meio urbano. 
Eventos naturais extremos estão relacionados à excepcionalidade, independentemente da gênese e do espaço geográfico em que atuam, são rótulos genéricos para definir uma gama de fenômenos que se caracterizam por acarretar sérios prejuízos às economias e às populações afetadas, com os mais frequentes e intensos ligados, direta ou indiretamente, à atmosfera (A. M. P. M. Brandão, 2001; C. A. F. Monteiro, 1976). Os impactos pluviais concentrados são considerados importantes eventos naturais extremos, com potencial de produzir desastres.

D. Goodin et al. (2004) explicam que os eventos climáticos extremos, tratados na perspectiva do fenômeno físico, são geralmente raros e para reconhecê-los e categorizálos é necessário a análise de registros abrangentes das séries históricas de dados meteorológicos. B. Wisner et al. (2003) apontam que, na perspectiva socioeconômica, os eventos extremos são compreendidos pelos danos de grande relevância que provocam, como óbitos, desabrigos, prejuízos financeiros, entre outros. Nesse sentido, a vulnerabilidade e resiliência dos grupos sociais são importantes aspectos para a análise.

Segundo J. B. Monteiro e M. E. Zanella (2013) há dificuldade em definir uma chuva extrema - evento extremo - devido à dinâmica e estrutura de cada cidade em relação à influência da urbanização na maior ou menor intensidade do impacto ocasionado por um episódio pluviométrico de forte intensidade.

M. E. Zanella, M. C. L. Sales e N. J. A. Abreu (2009) consideram, para a Cidade de Fortaleza, que as precipitações diárias a partir de $60 \mathrm{~mm}$ causam impactos significativos. De acordo com análises realizadas entre 1974 a 2008, afirmam que há uma tendência de anos mais chuvosos serem também os que apresentam maior número de eventos intensos. Já J. L. S. Olímpio et al. (2013), analisando os totais pluviométricos na série histórica compreendida entre 1974 a 2012, classificam os eventos de chuva extremos (expressivos e insuportáveis quanto ao potencial de impacto) quando ultrapassam $100 \mathrm{~mm} /$ dia, conforme apresentado no QUADRo I a seguir.

QuAdro I - Classificação das chuvas em relação ao potencial de impactos hidrometeóricos na Cidade de Fortaleza.

TABLE I - Classification of rains in relation to the potential hydrometeorological impacts on the city of Fortaleza.

\begin{tabular}{|c|c|c|}
\hline $\begin{array}{c}\text { Evento } \\
\text { pluvial }\end{array}$ & $\begin{array}{c}\text { Intervalos } \\
\text { (mm/dia) }\end{array}$ & $\begin{array}{c}\text { Potencial de } \\
\text { impacto }\end{array}$ \\
\hline Inexpressivo & De 0,1 a 10 & Insignificante \\
\hline Normal & $>10$ a 60 & Assimilável \\
\hline Intenso & $>60$ a 100 & $\begin{array}{c}\text { Significativo mas } \\
\text { suportável }\end{array}$ \\
\hline Extremo & $>100$ & Expressivo e insuportável \\
\hline
\end{tabular}

Fonte/Source: J. L. S. Olímpio et al. (2013)
A classificação da intensidade dos eventos de chuva considerando os totais pluviométricos registrados na Cidade de Fortaleza, realizada por J. L. S. Olímpio et al. (2013), serve de referência para o presente estudo, em destaque a classe de evento extremo. A utilização dessa classificação é necessária considerando que esse tipo de análise não está contemplado no escopo da avaliação aqui proposta.

$\mathrm{Na}$ presente proposta são primordialmente avaliadas as informações sobre a espacialização dos problemas registrados na integralidade dos dias que compõem a série temporal (2013-2015). Subsequentemente essas informações são correlacionadas com o padrão de ocorrência dos eventos naturais. Essa integração serve à compreensão da distribuição sazonal e repercussão espacial dos fenômenos relativos aos impactos ocasionados pelas chuvas. Na ordem, são analisados primeiramente os problemas e depois o evento natural deflagrador, privilegiando a espacialização.

Os eventos pluviais, como fator natural, são avaliados e classificados em termos de importância, para se estabelecer uma relação entre os impactos causados e o potencial das chuvas. O que se enfatiza são os eventos impactantes na cidade no período considerado, com repercussão nos principais meios de comunicação local e órgãos públicos de atendimento emergencial. Os eventos extremos são importantes nessa perspectiva analítica, mas não exclusivamente.

Em síntese, os procedimentos investigativos adotados para a avaliação dos impactos das chuvas na Cidade de Fortaleza no triênio 2013, 2014 e 2015, partem da coleta de informações cotidianamente nos portais de notícias on-line dos jornais locais: O Povo, Diário do Nordeste, Tribuna do Ceará e 0 Estado. Todas as reportagens sobre chuvas ou efeitos do clima na Cidade de Fortaleza e no Estado do Ceará foram coletadas, selecionadas, analisadas, catalogadas em meio digital e organizadas por data: ano, mês e dia. Foram extraídas informações sobre: totais pluviométricos, impactos na cidade, principais locais atingidos, órgãos envolvidos, manchetes de destaque e fontes das informações. Essas informações foram corroboradas com os dados disponíveis nos boletins de ocorrência do órgão municipal de Defesa Civil (COMDEC-For) e de trânsito (AMC).

As informações reportadas serviram de indicadores dos problemas causados à cidade por conta dos eventos pluviais. A avaliação da importância da chuva como evento natural foi integrada às informações sobre os impactos na organização sócioespacial. Após a identificação dos impactos reportados, foi realizada a correlação do evento deflagrador do impacto com os totais pluviométricos registrados nos postos meteorológicos considerados. 
São utilizados os totais pluviométricos diários oficiais disponibilizados pela FUNCEME para os anos de 2013, 2014 e 2015, em quatro postos de coleta de dados localizados na Cidade de Fortaleza (QUADRo II). As informações foram organizadas enfatizando os dias de chuvas com impactos registrados.

As precipitações pluviométricas registradas nos dias de chuvas com impactos na cidade representam o fator natural no Sistema Clima Urbano. A importância das chuvas nos dias em destaque é indicada pela distribuição e abrangência espacial, médias dos totais pluviométricos coletados e a ocorrência de eventos extremos e intensos.

0 indicador de abrangência e distribuição espacial das chuvas considera a ocorrência de precipitações nas diversas regiões da cidade, coletadas nos postos considerados, de modo a abranger a integralidade do território municipal, conforme estabelecido no QUADRo III.

Ao abordar as quatro estações pluviométricas localizadas em diferentes regiões da cidade pretende-se obter uma dimensão da abrangência espacial das chuvas no território. De acordo com o critério sugerido entende-se que, se o evento de chuva foi registrado em um posto pluviométrico ele é considerado concentrado, ao passo que, se foi registrado em todos os postos, é classificado como generalizado.

O indicador de relevância das chuvas, em dias com impactos registrados na cidade, tem como base a média das precipitações registradas nos postos de coleta e a severidade do evento pluvial. Nesse ínterim, se utiliza a classificação de J.L.S. Olímpio et al. (2013) realizada para a Cidade de Fortaleza, conforme mostra o QUADRO IV.

0 indicador da ocorrência de eventos extremos de chuva baseia-se nos registros de precipitações maiores que $100 \mathrm{~mm}$ nos postos meteorológicos considerados e distribuição espacial destes eventos. Esse índice, que define eventos extremos de chuva, foi baseado na classificação de J. L. S. Olímpio et al. (2013) para a Cidade de Fortaleza, conforme apresentado no QUADRo V.

A avaliação da importância das chuvas proporciona uma visão sobre a relação entre os impactos hidrometeóricos noticiados e o potencial dos eventos pluviais como fator natural. Nesse contexto é possível desvendar a relação entre o tipo de evento pluvial, em termos de intensidade ( $\mathrm{mm} / \mathrm{dia})$ e distribuição espacial, e os impactos deflagrados na cidade, acentuando ou atenuando a importância dos eventos naturais e relevando as possíveis deficiências de infraestruturas de drenagem e ocupação inadequada dos ambientes com elevada fragilidade ambiental.
Quadro II - Cidade de Fortaleza (2013, 2014 e 2015) - totais de precipitação registrados nos postos pluviométricos nos dias de chuvas com impactos registrados.

TABLE II - City of Fortaleza (2013, 2014 and 2015) - total rainfall recorded in the rain gauge stations on days of rainfall with recorded impacts.

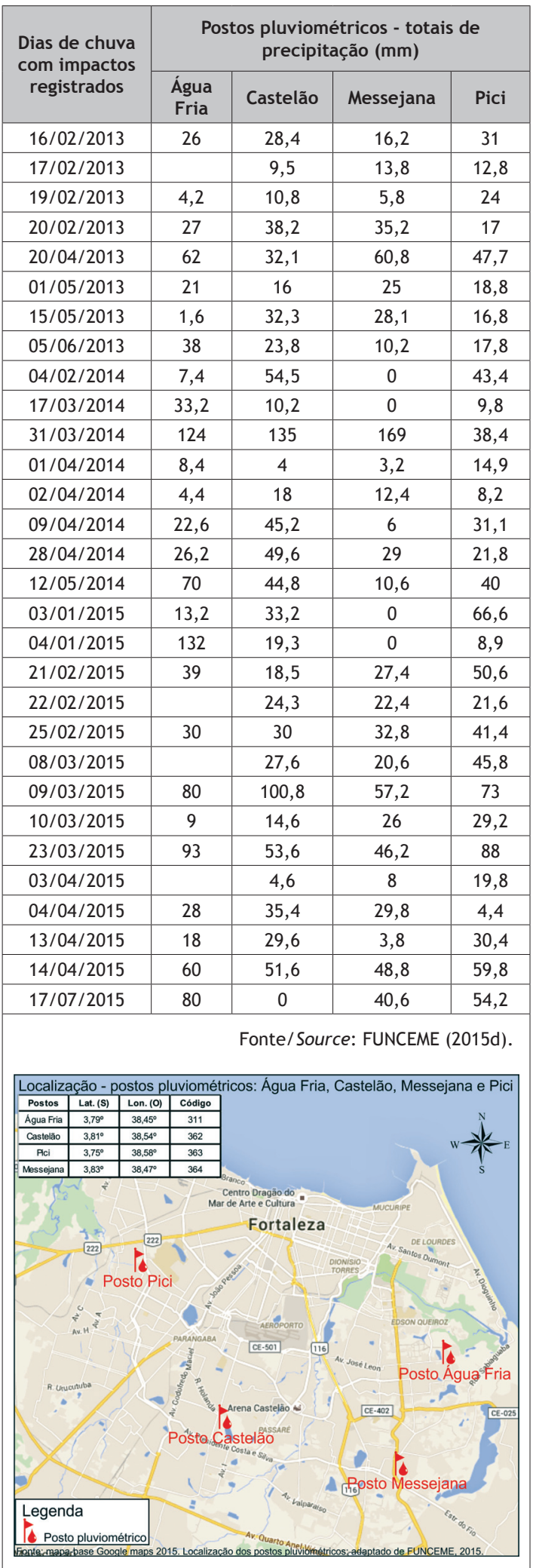


QUADRo III - Indicador de abrangência e distribuição espacial das chuvas na Cidade de Fortaleza.

TAвLE III - Indicator of coverage and spatial distribution of rainfall in the city of Fortaleza.

\begin{tabular}{|c|c|}
\hline Registros de chuva & Classificação da chuva \\
\hline Um posto pluviométrico & Concentrada \\
\hline Dois postos pluviométricos & Mal distribuída \\
\hline Três postos pluviométricos & Bem distribuída \\
\hline Quatro postos pluviométricos & Generalizadas \\
\hline
\end{tabular}

QUADRO IV - Indicador de relevância das chuvas na Cidade de Fortaleza. TABLE IV - Indicator of rainfall relevance in the city of Fortaleza.

\begin{tabular}{|c|c|c|}
\hline Classes $(\mathbf{m m})$ & Classificação da chuva & Evento pluvial \\
\hline 0,1 a 10 & Baixa relevância & Inexpressivo \\
\hline$>10$ a 60 & Média relevância & Normal \\
\hline$>60$ a 100 & Alta relevância & Intenso \\
\hline$>100$ & Extrema relevância & Extremo \\
\hline
\end{tabular}

Fonte: adaptado de J. L. S. Olímpio et al., 2013. Source: adapted fom J. L. S. Olímpio et al., 2013.

QUADRo V - Indicador da ocorrência de eventos pluviais extremos na Cidade de Fortaleza.

$T_{A B L E} V$ - Indicator of the occurrence of extreme rainfall events in the city of Fortaleza.

\begin{tabular}{|c|c|}
\hline $\begin{array}{c}\text { Classificação do evento } \\
\text { extremo }\end{array}$ & Ocorrência espacial \\
\hline $\begin{array}{c}\text { Evento extremo } \\
\text { concentrado }\end{array}$ & Um posto pluviométrico \\
\hline $\begin{array}{c}\text { Eventos extremos } \\
\text { medianamente abrangentes }\end{array}$ & Dois postos pluviométricos \\
\hline $\begin{array}{c}\text { Eventos extremos bem } \\
\text { abrangentes }\end{array}$ & Três postos pluviométricos \\
\hline $\begin{array}{c}\text { Eventos extremos } \\
\text { generalizados }\end{array}$ & Quatro postos pluviométricos \\
\hline
\end{tabular}

Fonte: adaptado de J. L. S. Olímpio et al., 2013. Source: adapted fom J. L. S. Olímpio et al., 2013.

Impactos hidrometeóricos registrados na Cidade de Fortaleza no triênio 2013, 2014 e 2015

Os principais resultados do estudo procedido apontaram que a maioria dos problemas decorrentes do impacto das chuvas na cidade de Fortaleza ocorre em comunidades com predominância de habitações precárias, evidenciados através dos diversos casos de destruição total ou parcial de imóveis residenciais, principalmente desabamentos e desestabilização das estruturas construídas. 0 padrão construtivo deficiente das estruturas físicas dos imóveis favorece à maior vulnerabilidade dos grupos sociais aos efeitos adversos das chuvas. Estes casos merecem atenção especial e prioritária dos serviços de atendimento de emergência, pois apresentam o mais elevado risco de danos humanos, como a possibilidade de óbitos. Políticas públicas de prevenção e redução dos riscos, satisfeitas através do ordenamento territorial, obras de drenagem, saneamento básico e produção habitacional formal, são necessárias para redução da vulnerabilidade da população aos impactos das chuvas.

Os impactos espacialmente generalizados na mobilidade de veículos automotivos, individuais e coletivos, revelam os significativos efeitos adversos das chuvas no sistema viário da cidade. Esses problemas estão historicamente relacionados ao dimensionamento insuficiente da rede física de drenagem pluvial, cujo agravamento é verificado através da extensiva remoção da cobertura vegetal e impermeabilização das superfícies naturais. Essas intervenções técnicas indiscriminadas contribuem para aumentar a velocidade do escoamento superficial e diminuir o tempo do pico de inundações nos cursos fluviais e corpos lacustres, assim como para rápidos alagamentos nas áreas de acumulação sazonal, com permanência do excedente hídrico por maior período de tempo.

Os eventos extremos de chuvas ocorreram em três dos 30 dias com problemas registrados na série temporal considerada. Além da importância em termos naturais, pela excepcionalidade, esse tipo de evento foi significativo pela quantidade de impactos causados na organização territorial, com maior número de ocorrências registradas pelos órgãos municipais de Defesa Civil e de Trânsito, o que denota maior extensão dos danos nas diversas regiões da cidade. A desorganização causada na mobilidade urbana é significativa, com várias vias interditadas e semáforos em pane, em função do impacto direto das águas e alagamentos decorrentes, provocando extensos congestionamentos de veículos.

A avaliação dos registros evidenciou que a distribuição espacial dos impactos hidrometeóricos na Cidade de Fortaleza ocorre de forma generalizada no território.

O setor nordeste da cidade concentra os bairros com maior renda média familiar e melhor padrão de infraestrutura urbana. Contudo, segundo os registros avaliados, apresentou um número elevado de impactos ocasionados pelas chuvas. Os problemas, nesse contexto socioespacial, se relacionaram principalmente a alagamentos em vias, com sérios transtornos no trânsito de veículos. Há que se destacar a elevada e generalizada impermeabilização do solo nessa região.

Conforme a espacialização dos dados avaliados, constatou-se que o cinturão periférico da cidade, setores centro-sul, sudoeste e noroeste, caracterizados pela baixa renda, apresentaram quase todos os problemas decorrentes dos fenômenos atmosféricos identificados. Esses setores apresentam as piores condições de renda média familiar e mais deficiente cobertura de infraestruturas urbanas, principalmente relacionadas 
à precária rede de drenagem de águas pluviais. Nesses contextos sócioespaciais foram observados alagamentos e inundações causando extensivos danos em vias e em residências, com forte desorganização urbana. Esses setores apresentam generalizada ocupação inadequada do sítio natural em relação à fragilidade ambiental, onde a supressão indiscriminada dos corpos hídricos e a impermeabilização predominante do solo em áreas de preservação contribuem significativamente para a extensão dos impactos das chuvas no meio urbano.

Na série temporal em questão, 53 dos 119 bairros foram atingidos pelos impactos hidrometeóricos (fig. 3). Entre esses bairros figuraram entre os mais impactados a Serrinha, a Aldeota, o Bom Jardim, o Conjunto Ceará e o Quintino Cunha, citados em mais de $40 \%$ dos registros. Entre as comunidades, pelo menos 16 foram frequentemente citadas. Quanto aos problemas na mobilidade, 32 vias de grande circulação foram afetadas, segundo os registros.
De acordo com a avaliação da distribuição espacial dos eventos naturais deflagrados pelas chuvas, o setor nordeste da cidade apresenta a maior diversidade desses eventos impactando o meio urbano. Os alagamentos predominam, mas também ocorrem inundações e mais raramente deslizamentos de terra e ressacas do mar.

Os alagamentos, combinados com inundações, predominam em toda a cidade, apresentando maior incidência, conforme os registros, no setor centro-sul, ao longo do Rio Cocó, no setor sudoeste e oeste, seguindo os principais canais fluviais da bacia do Rio Maranguapinho. Destacam-se também no setor noroeste, confluência com o litoral oeste da Cidade de Fortaleza.

Dos 53 bairros afetados pelas chuvas, 36 foram impactados por alagamentos e inundações, com destaque ao Bairro Serrinha, o mais afligido, segundo os registros. Somente por alagamentos como único evento, foram impactados 14 bairros, entre eles a Aldeota, que

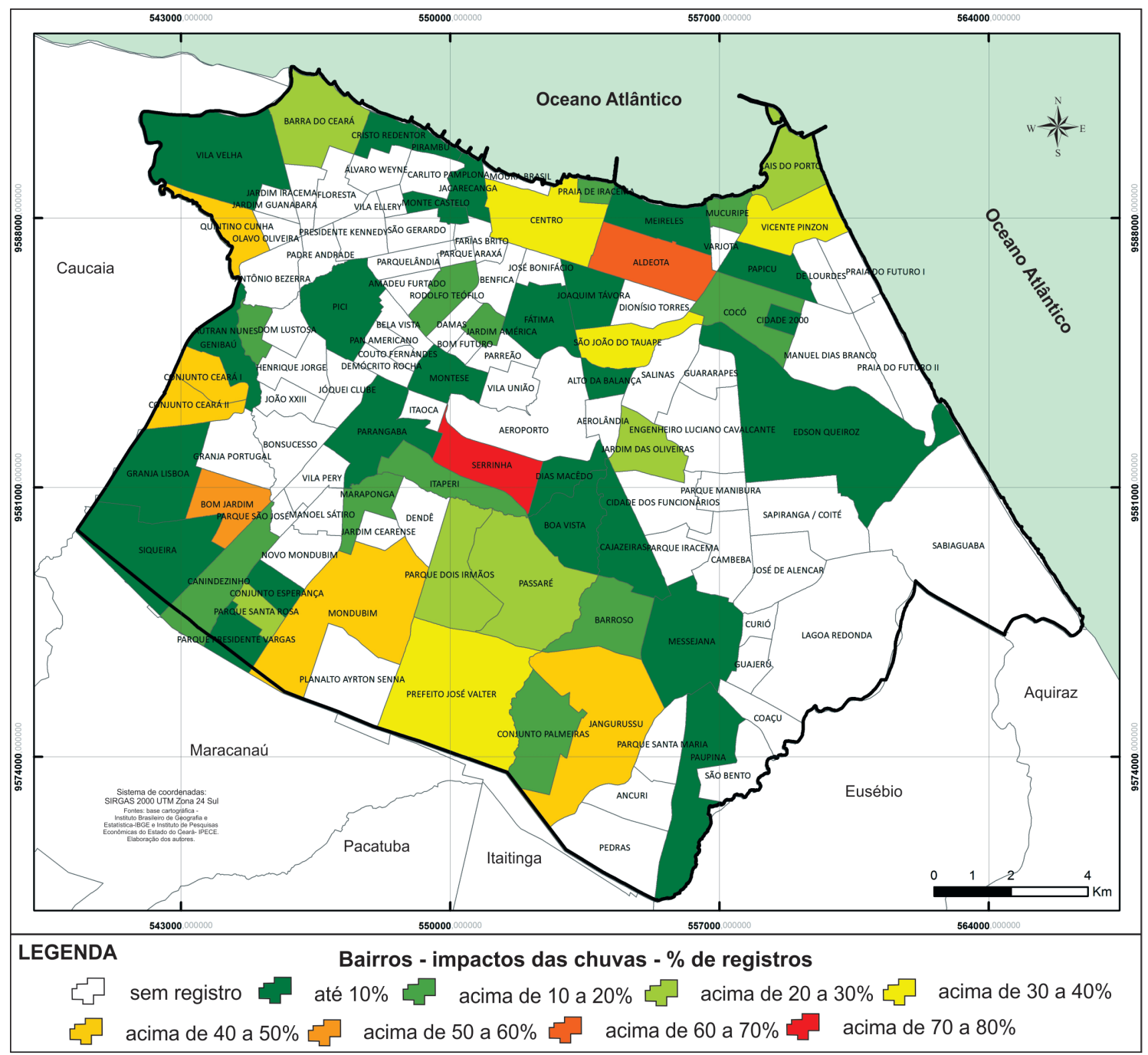

Fig. 3 - Cidade de Fortaleza: bairros mais impactados pelas chuvas em 2013, 2014 e 2015.

Fig. 3 - City of Fortaleza: neighbourhoods most impacted by the rains in 2013, 2014 and 2015. 
embora figure como o segundo bairro mais afetado pelas chuvas, apresenta somente problemas no trânsito. Três bairros foram impactados por eventos combinados de alagamentos, inundações e deslizamento de terra em encosta de dunas densamente ocupadas: Barra do Ceará, Centro e Vicente Pinzón, todos localizados no litoral, em trechos diferentes.

Somente o bairro Cais do Porto foi impactado por eventos combinados de alagamentos, inundações e ressacas do mar, em destaque a Comunidade da Praia do Titanzinho. $\mathrm{Na}$ fig. 4, a seguir, estão presentes os principais eventos naturais deflagrados pelas chuvas que impactaram os bairros de Fortaleza, demonstrando a distribuição espacial dos problemas.

Interpretando-se a relação entre o mapa dos sistemas ambientais que formam o sítio urbano (fig. 1) e os mapas que espacializam os impactos das chuvas (fig. 3 e 4) corrobora-se que os ambientes mais suscetíveis à ocorrência de inundações são as planícies fluviais, lacustres, flúviolacustres e flúviomarinhas. As áreas de inundação sazonal também são suscetíveis à ocorrência de inundações e alagamentos, agravadas pela densidade da ocupação e pela deficiência da rede de drenagem artificial, precariamente instalada e mal dimensionada.

No campo de dunas, altamente modificado pela ocupação urbana desordenada, as vertentes geralmente acima de $50 \mathrm{~m}$ de altitude, com inclinações mais acentuadas, apresentam-se com elevada suscetibilidade às corridas de lama de alta velocidade, deflagradas durante os episódios de chuvas intensas e extremas. A alta densidade da ocupação nas encostas, associada a profundas alterações na drenagem natural, potencializam a ocorrência desses eventos, sobretudo nos setores ocupados por assentamentos precários.

Os principais problemas ocasionados pelos impactos hidrometeóricos na Cidade de Fortaleza estão representados na fig. 5 a seguir, onde foram sistematizadas fotografias que representam como os meios

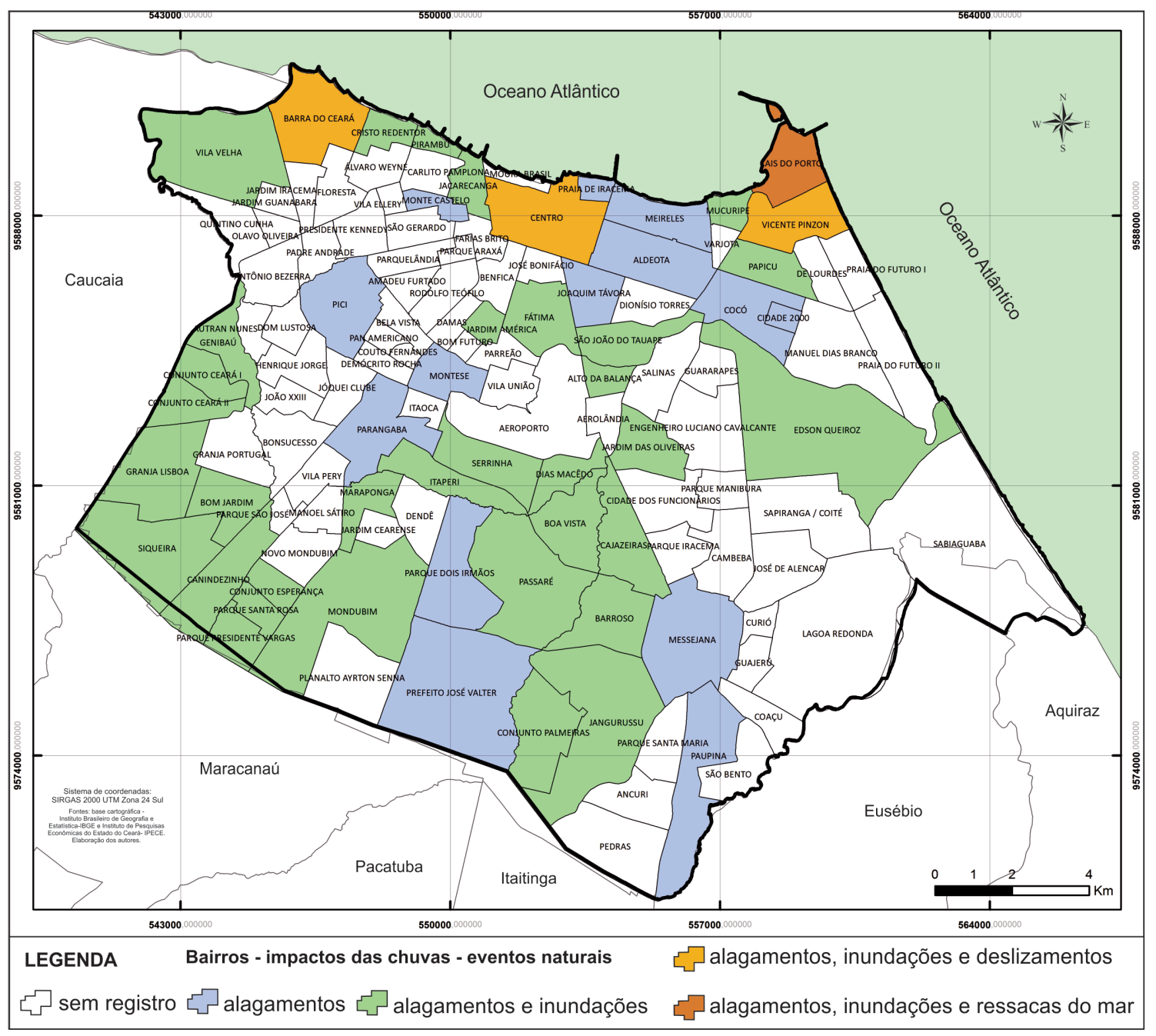

Fig. 4 - Cidade de Fortaleza: bairros impactados por eventos naturais decorrentes das chuvas em 2013, 2014 e 2015.

Fig. 4 - City of Fortaleza: Neighbourhoods impacted by natural events resulting from the rains in 2013, 2014 and 2015 
de comunicação retrataram os problemas evidenciados pela ação das chuvas na cidade.

No ano de 2013 a maioria dos dias com impactos registrados, deflagrados pelas chuvas, ocorreu durante a quadra chuvosa, nos meses de fevereiro, abril e maio, com somente um dia na pós-estação chuvosa, no mês de junho. Não foram registrados dias de chuva com impactos na pré-estação chuvosa.

Os principais impactos causados à integridade da cidade em 2013 foram os alagamentos e as inundações, que atingiram principalmente vias e residências (QUADRo VI). Os impactos nas vias causaram problemas generalizados no trânsito, danos nas infraestruturas viárias, de saneamento e drenagem. Ocorreram também danos em veículos com queda em bueiros, valas e galerias ou submersão nos alagamentos. Os danos nas residências foram principalmente provocados por desabamentos.
No ano de 2013, nos oito dias de chuvas com impactos registrados, ocorreram sete dias com chuvas de média relevância e um dia com baixa relevância. Foram sete dias com chuvas generalizadas e um dia com chuvas bem distribuídas. Não ocorreram eventos extremos de chuva. De uma forma geral, as chuvas foram consideradas de média relevância e generalizadas. Não houve nenhum evento pluvial extremo, portanto, ausente, nos dias com impactos hidrometeóricos registrados na Cidade de Fortaleza.

Nos oito dias de chuvas com impactos registrados na cidade foram realizadas 136 ações de emergência com ocorrências registradas pela Coordenadoria Municipal de Defesa Civil - COMDEC, da Prefeitura Municipal de Fortaleza - PMF.

De acordo com a Fundação Cearense de Meteorologia e Recursos Hídricos (FUNCEME, 2015a) a quadra chuvosa no ano de 2013 - entre fevereiro e maio - no Estado do Ceará
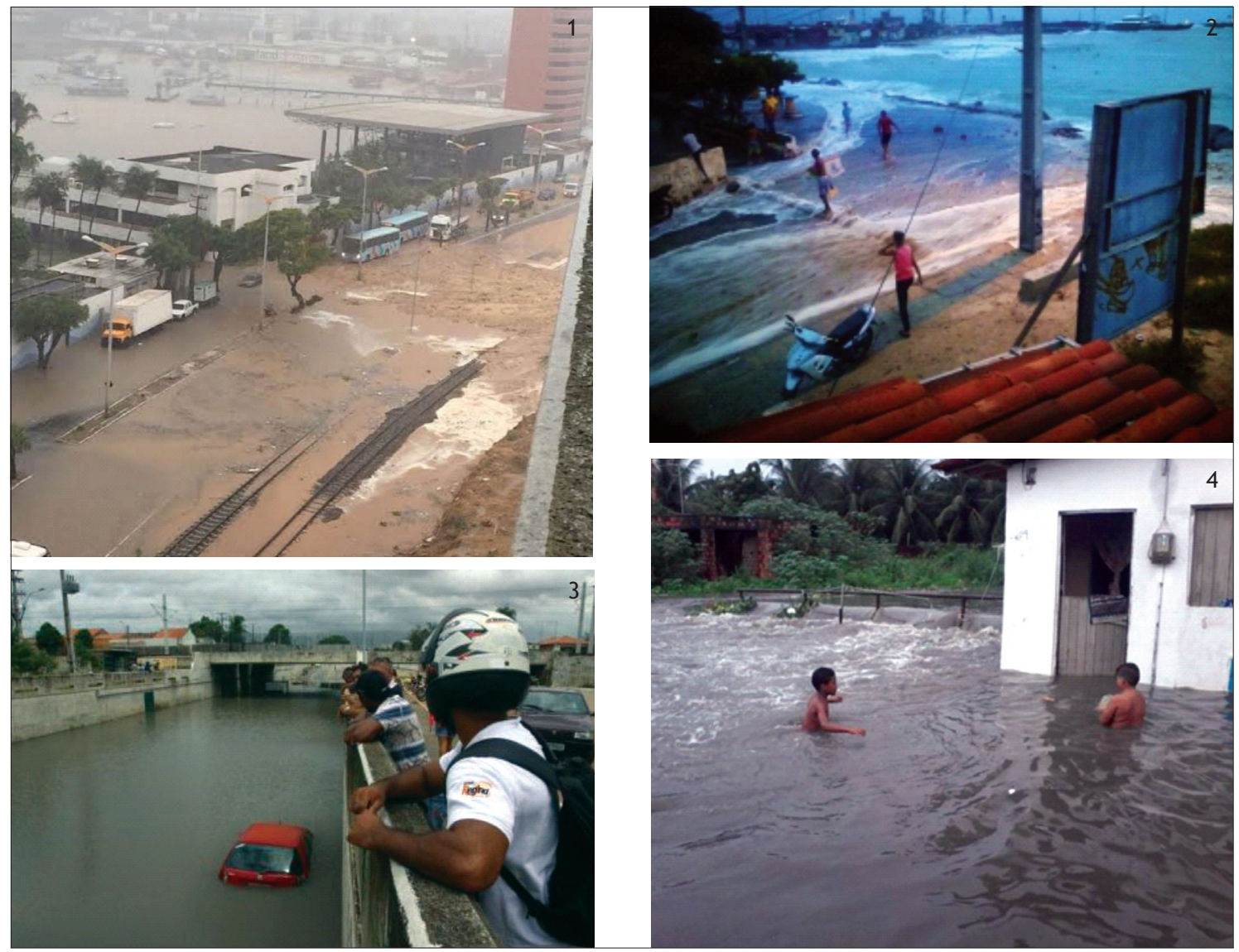

Fig. 5 - Cidade de Fortaleza: impactos das chuvas - deslizamento, inundação e alagamento com danos em vias e residências em 2013, 2014 e 2015 (Fonte: O Povo, 2015; Diário do Nordeste, 2015; Tribuna do Ceará, 2015; O Estado, 2015. Nota: 1. 03/01/15: Deslizamento de terra em duna. Morro Santa Terezinha, Bairro Vicente Pinzon; 2. 01/04/2014: Avanço do mar. Praia do Titanzinho, Comunidade do Serviluz, Bairro Cais do Porto; 3. 01/04/2014: Alagamento em via. Túnel na Av. Perimetral com linha do Metrofor. Bairro Mondubim; 4. 08/03/2015: Inundação. Conjunto Mirassol, Bairro Serrinha).

Fig. 5 - City of Fortaleza: Impacts of rain - landslide, innundation and flooding with damage to roads and homes in 2013, 2014 and 2015 (Source: O Povo, 2015; Diário do Nordeste, 2015; Tribuna do Ceará, 2015; O Estado, 2015. Note: 1. 03/01/15: Landslide in dune land. Morro Santa Terezinha, Vicente Pinzon neighbourhood; 2. 01/04/2014: Sea advancement. Titanzinho Beach, Serviluz Community, neighbourhood of Cais do Porto; 3. 01/04/2014: Flooding on the road. Tunnel at Av Perimetral with Metrofor line. Mondubim Neighbourhood; 4. 08/03/2015: Flood. Conjunto Mirassol, Serrinha neighbourhood. 
QUADRo VI - Cidade de Fortaleza (2013) - impactos das chuvas e importância do fator natural.

TABLE VI - City of Fortaleza (2013) - impacts of rain and importance of the natural factor.

\begin{tabular}{|c|c|c|c|c|c|c|c|c|c|}
\hline \multirow{2}{*}{\multicolumn{2}{|c|}{2013}} & \multicolumn{4}{|c|}{ FEV } & ABR & \multicolumn{2}{|c|}{ MAI } & \multirow{2}{*}{$\begin{array}{c}\text { JUN } \\
05\end{array}$} \\
\hline & & 16 & 17 & 19 & 20 & 20 & 01 & 15 & \\
\hline \multicolumn{2}{|c|}{ Sistema atmosférico } & ZCIT & ZCIT & ZCIT & $\mathrm{ZCIT}$ & VCAN & ZCIT & VCAN & OL e Brisas \\
\hline \multicolumn{2}{|c|}{ Chuvas: média (mm) } & 25,4 & 9,0 & 11,2 & 29,4 & 50,7 & 20,2 & 19,7 & 22,5 \\
\hline \multicolumn{2}{|c|}{ Relevância da chuva } & M & B & M & M & M & M & $M$ & M \\
\hline \multicolumn{2}{|c|}{ Abrangência espacial } & G & $\mathrm{BD}$ & G & G & G & G & G & G \\
\hline \multicolumn{2}{|c|}{ Eventos extremos } & A & $A$ & A & A & A & A & $A$ & A \\
\hline \multicolumn{2}{|c|}{ Alagamentos } & $x$ & $x$ & $x$ & $x$ & $x$ & $x$ & $x$ & $x$ \\
\hline \multicolumn{2}{|c|}{ Inundações } & $x$ & $x$ & & $x$ & & & & \\
\hline \multicolumn{10}{|c|}{ Deslizamento } \\
\hline \multicolumn{2}{|c|}{ Trânsito } & & & $x$ & $x$ & $x$ & $x$ & $x$ & $x$ \\
\hline \multicolumn{10}{|c|}{ Incêndios } \\
\hline \multirow{4}{*}{ Danos } & Residências & $x$ & $x$ & $x$ & $x$ & $x$ & $x$ & $x$ & $x$ \\
\hline & Vias públicas & & & $x$ & $x$ & $x$ & & & \\
\hline & Saneamento & & & $x$ & $x$ & $x$ & & & \\
\hline & Veículos & & & & $x$ & & & & \\
\hline \multirow{2}{*}{ Tombamento } & Árvores & & & & & & & & \\
\hline & Postes & & & & & & & & \\
\hline \multirow{4}{*}{ Interrupção } & Aeroporto & & & & & & & & \\
\hline & Hospitais & & & & & & & & \\
\hline & Eletricidade & & & & & & & & \\
\hline & Obras & & & & & & & & \\
\hline Defesa Civil & Ocorrências & 14 & & 53 & 43 & 19 & & 02 & 05 \\
\hline
\end{tabular}

Legenda:

\begin{tabular}{|l|l|l|l|}
\hline Relevância da chuva & Abrangência espacial & \multicolumn{1}{|c|}{ Eventos extremos } & \multicolumn{1}{c|}{ Sistemas atmosféricos } \\
\hline$B=$ baixa & $\mathrm{C}=$ Concentrada & $\mathrm{C}=$ concentrado & ZCIT = Zona de Convergência Intertropical \\
\hline $\mathrm{M}=$ média & $\mathrm{MD}=$ Mal distribuída & $\mathrm{MA}=$ medianamente abrangentes & VCAN = Vórtices Ciclônicos de Altos Níveis \\
\hline $\mathrm{A}=$ alta & $\mathrm{BD}=$ Bem distribuída & $\mathrm{BA}=$ bem abrangentes & $\mathrm{OL}=$ Ondas de Leste \\
\hline $\mathrm{E}=$ extrema & $\mathrm{G}=$ Generalizadas & $\mathrm{G}=$ generalizados & Brisas = Sistema de Brisas \\
\hline & & $\mathrm{A}=$ ausente & \\
\hline
\end{tabular}

Fonte/Source: O Povo (2015); Diário do Nordeste (2015); Tribuna do Ceará (2015); O Estado (2015); FUNCEME (2015d).

apresentou totais de precipitação 37,7\% abaixo da média histórica, refletidos em todas as regiões do estado.

No ano de 2014 foram identificados oito dias com impactos hidrometeóricos registrados na Cidade de Fortaleza deflagrados por chuvas. Todos ocorreram em dias concentrados na quadra chuvosa.

Os principais impactos registrados na cidade foram os alagamentos, as inundações, deslizamentos de terra e problemas generalizados no trânsito (QUADRo VII). Também ocorreram incêndios e danos em residências, vias, em infraestruturas de saneamento e veículos. Houve o tombamento de árvores em vias. No dia 04 de fevereiro de 2014 o Aeroporto Internacional Pinto Martins teve as operações de pousos e decolagens interrompidas temporariamente por conta dos eventos pluviais.

No ano de 2014, nos oito dias de chuvas com impactos hidrometeóricos registrados, ocorreu um dia de chuva de baixa relevância, seis dias de chuvas de média relevância e um dia de chuva de extrema relevância (31/03/2014). Foram seis dias com chuvas generalizadas e dois dias com chuvas bem distribuídas. Ocorreram três eventos extremos de chuvas, todos no dia 31 de março, considerados, portanto, bem abrangentes espacialmente.

Em 2014, na Cidade de Fortaleza, a maioria das chuvas foi classificada como de média relevância e generalizada. Foram identificadas nos oito dias de chuvas com impactos 
QuAdro VII - Cidade de Fortaleza (2014) - impactos das chuvas e importância do fator natural.

TABLE VII - City of Fortaleza (2014) - impacts of rain and importance of the natural factor.

\begin{tabular}{|c|c|c|c|c|c|c|c|c|c|}
\hline \multirow{2}{*}{\multicolumn{2}{|c|}{2014}} & FEV & \multicolumn{2}{|c|}{ MAR } & \multicolumn{4}{|c|}{ ABR } & \multirow{2}{*}{$\begin{array}{r}\text { MAI } \\
12\end{array}$} \\
\hline & & 04 & 17 & 31 & 01 & 02 & 09 & 28 & \\
\hline \multicolumn{2}{|c|}{ Sistema atmosférico } & VCAN & $\mathrm{ZCIT}$ & ZCIT VCAN & ZCIT VCAN & ZCIT VCAN & ZCIT & ZCIT & ZCIT \\
\hline \multicolumn{2}{|c|}{ Chuvas: média (mm) } & 26,3 & 13,3 & 116,6 & 7,6 & 10,8 & 26,2 & 31,7 & 41,4 \\
\hline \multicolumn{2}{|c|}{ Relevância da chuva } & M & M & $\mathrm{E}$ & B & M & M & $M$ & M \\
\hline \multicolumn{2}{|c|}{ Abrangência espacial } & BD & $\mathrm{BD}$ & G & G & G & G & G & G \\
\hline \multicolumn{2}{|c|}{ Eventos extremos } & A & A & BA & A & A & A & A & A \\
\hline \multicolumn{2}{|c|}{ Alagamentos } & $x$ & $x$ & $x$ & $x$ & $x$ & $x$ & $x$ & $x$ \\
\hline \multicolumn{2}{|c|}{ Inundações } & $x$ & & $x$ & $x$ & $x$ & $x$ & $x$ & \\
\hline \multicolumn{2}{|c|}{ Deslizamento } & & & $x$ & & & & & \\
\hline \multicolumn{2}{|c|}{ Trânsito } & $x$ & $x$ & $x$ & $x$ & $x$ & $x$ & $x$ & $x$ \\
\hline \multicolumn{2}{|c|}{ Incêndios } & & & $x$ & & & & & \\
\hline \multirow{4}{*}{ Danos } & Residências & $x$ & & $x$ & $x$ & $x$ & $x$ & & \\
\hline & Vias públicas & & & $x$ & & & & & $x$ \\
\hline & Saneamento & $x$ & & & & & & & \\
\hline & Veículos & & & & & $x$ & & & \\
\hline \multirow{2}{*}{ Tombamento } & Árvores & $x$ & & & $x$ & & & & \\
\hline & Postes & & & & & & & & \\
\hline \multirow{4}{*}{ Interrupção } & Aeroporto & $x$ & & & & & & & \\
\hline & Hospitais & & & & & & & & \\
\hline & Eletricidade & & & & & & & & \\
\hline & Obras & $x$ & & & & & & & \\
\hline Defesa civil & Ocorrências & 38 & & 168 & 43 & 13 & 43 & & \\
\hline
\end{tabular}

Legenda:

\begin{tabular}{|l|l|l|l|}
\hline Relevância da chuva & Abrangência espacial & \multicolumn{1}{|c|}{ Eventos extremos } & \multicolumn{1}{c|}{ Sistemas atmosféricos } \\
\hline $\mathrm{B}=$ baixa & $\mathrm{C}=$ Concentrada & $\mathrm{C}=$ concentrado & ZCIT = Zona de Convergência Intertropical \\
\hline $\mathrm{M}=$ média & $\mathrm{MD}=$ Mal distribuída & $\mathrm{MA}=$ medianamente abrangentes & $\mathrm{VCAN}=$ Vórtices Ciclônicos de Altos Níveis \\
\hline $\mathrm{A}=$ alta & $\mathrm{BD}=$ Bem distribuída & $\mathrm{BA}=$ bem abrangentes & $\mathrm{OL}=$ Ondas de Leste \\
\hline $\mathrm{E}=$ extrema & $\mathrm{G}=$ Generalizadas & $\mathrm{G}=$ generalizados & Brisas = Sistema de Brisas \\
\hline & & $\mathrm{A}=$ ausente & \\
\hline
\end{tabular}

Fonte/Source: O Povo (2015); Diário do Nordeste (2015); Tribuna do Ceará (2015); O Estado (2015); FUNCEME (2015d).

deflagrados na cidade em 2014, 305 ocorrências de ações emergenciais registradas pela Defesa Civil de Fortaleza.

As precipitações na quadra chuvosa de 2014 ficaram $24 \%$ abaixo da média histórica. A média dos quatro meses é de $607,4 \mathrm{~mm}$ e as precipitações acumuladas no período foram de $461,9 \mathrm{~mm}$. A Macrorregião do Litoral de Fortaleza apresentou déficit de $-25,30 \%$ na precipitação pluviométrica em 2014 (FUNCEME, 2015b).

No último ano do período considerado, em 2015 (janjul), na Cidade de Fortaleza, foram registrados impactos hidrometeóricos em 14 dias. A maioria dos impactos registrados ocorreu durante a quadra chuvosa, no entanto na pré-estação foram registrados dois dias de chuvas com impactos e um dia na pós-estação.
Os principais impactos na cidade em 2015 foram os alagamentos, as inundações, deslizamento de terra, problemas generalizados no trânsito (QUADRO VIII). Registaram-se também incêndios decorrentes das chuvas, danos em residência, vias, infraestruturas de saneamento e em veículos. Identificaram-se interrupções temporárias no atendimento em hospital e no fornecimento de energia elétrica por conta dos impactos deflagrados pelas chuvas. Nos 14 de dias de chuvas com impactos a Defesa Civil Municipal atendeu a 312 ocorrências com chamados emergenciais.

$\mathrm{Na}$ análise do fator natural em 2015, nos 14 dias com impactos hidrometeóricos na Cidade de Fortaleza, ocorreu um dia com chuvas de baixa relevância, 11 dias com chuvas classificadas como de média relevância 
QUADRo VIII - Cidade de Fortaleza (2015): impactos das chuvas e importância do fator natural.

TABLE VIII - City of Fortaleza (2015): Impacts of rainfall and importance of natural factor.

\begin{tabular}{|c|c|c|c|c|c|c|c|c|c|c|c|c|c|c|c|}
\hline \multirow{2}{*}{\multicolumn{2}{|c|}{2015}} & \multicolumn{2}{|c|}{ JAN } & \multicolumn{3}{|c|}{ FEV } & \multicolumn{4}{|c|}{ MAR } & \multicolumn{4}{|c|}{$A B R$} & \multirow{2}{*}{$\begin{array}{c}\text { JUL } \\
17\end{array}$} \\
\hline & & 03 & 04 & 21 & 22 & 25 & 08 & 09 & 10 & 23 & 03 & 04 & 13 & 14 & \\
\hline \multicolumn{2}{|c|}{ Sistema atmosférico } & $\begin{array}{c}\text { VCAN } \\
\text { OL }\end{array}$ & $\begin{array}{c}\text { VCAN } \\
\text { OL }\end{array}$ & $\mathrm{ZCIT}$ & $\begin{array}{c}\text { ZCIT } \\
\text { VCAN }\end{array}$ & ZCIT & ZCIT & ZCIT & ZCIT & ZCIT & $\begin{array}{c}\text { ZCIT } \\
\text { VCAN }\end{array}$ & $\begin{array}{c}\text { ZCIT } \\
\text { VCAN }\end{array}$ & ZCIT & ZCIT & $\mathrm{OL}$ \\
\hline \multicolumn{2}{|c|}{ Chuvas: média (mm) } & 28,3 & 40,1 & 33,9 & 17,1 & 33,6 & 23,5 & 77,8 & 19,7 & 70,2 & 8,1 & 24,4 & 20,5 & 55,1 & 43,7 \\
\hline \multicolumn{2}{|c|}{ Relevância da chuva } & M & M & M & M & M & M & A & M & A & B & $M$ & M & M & $M$ \\
\hline \multicolumn{2}{|c|}{ Abrangência espacial } & $\mathrm{BD}$ & BD & G & $\mathrm{BD}$ & G & $\mathrm{BD}$ & $\mathrm{BD}$ & G & G & $B D$ & G & G & G & $\mathrm{BD}$ \\
\hline \multicolumn{2}{|c|}{ Eventos extremos } & A & MA & $A$ & A & A & A & MA & A & A & A & A & $A$ & A & A \\
\hline \multicolumn{2}{|c|}{ Alagamentos } & $x$ & $x$ & $x$ & $x$ & & $x$ & $x$ & $x$ & $x$ & $x$ & $x$ & & $x$ & $x$ \\
\hline \multicolumn{2}{|c|}{ Inundações } & $x$ & & & $x$ & & $x$ & $x$ & & $x$ & $x$ & $x$ & & $x$ & $x$ \\
\hline \multicolumn{2}{|c|}{ Deslizamento } & $x$ & & & & & & & & & & & & & \\
\hline \multicolumn{2}{|c|}{ Trânsito } & $x$ & $x$ & $x$ & $x$ & & $x$ & $x$ & $x$ & & & $x$ & $x$ & & $x$ \\
\hline \multicolumn{2}{|c|}{ Incêndios } & & & & & & & $x$ & & & & & & & \\
\hline \multirow{4}{*}{ 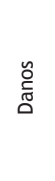 } & Residências & $x$ & & & $x$ & $x$ & $x$ & $x$ & & $x$ & & $x$ & & $x$ & \\
\hline & Vias públicas & $x$ & & & & & & & & & & & & $x$ & \\
\hline & Saneamento & $x$ & & $x$ & & & & & & & & & & & \\
\hline & Veículos & & & & & & & & $x$ & $x$ & & & & & $x$ \\
\hline \multirow{2}{*}{ 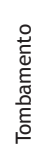 } & Árvores & & & $x$ & & & $x$ & & $x$ & $x$ & & & & & $x$ \\
\hline & Postes & $x$ & & & & & & & & & & & & & \\
\hline \multirow{4}{*}{ 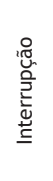 } & Aeroporto & & & & & & & & & & & & & & \\
\hline & Hospitais & & $x$ & & & & & & & & & & & & \\
\hline & Eletricidade & & $x$ & & & & & & & & & & & & \\
\hline & Obras & & & & & & & & & & & & & & \\
\hline 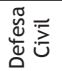 & Ocorrências & 107 & & 13 & & & 82 & & 66 & 31 & 10 & & & & 3 \\
\hline
\end{tabular}

Legenda:

\begin{tabular}{|l|l|l|l|}
\hline Relevância da chuva & Abrangência espacial & \multicolumn{1}{|c|}{ Eventos extremos } & \multicolumn{1}{c|}{ Sistemas atmosféricos } \\
\hline $\mathrm{B}=$ baixa & $\mathrm{C}=$ Concentrada & $\mathrm{C}=$ concentrado & $\mathrm{ZCIT}=$ Zona de Convergência Intertropical \\
\hline $\mathrm{M}=$ média & $\mathrm{MD}=$ Mal distribuída & $\mathrm{MA}=$ medianamente abrangentes & $\mathrm{VCAN}=$ Vórtices Ciclônicos de Altos Níveis \\
\hline $\mathrm{A}=$ alta & $\mathrm{BD}=$ Bem distribuída & $\mathrm{BA}=$ bem abrangentes & $\mathrm{OL}=$ Ondas de Leste \\
\hline $\mathrm{E}=$ extrema & $\mathrm{G}=$ Generalizadas & $\mathrm{G}=$ generalizados & Brisas = Sistema de Brisas \\
\hline & & $\mathrm{A}=$ ausente & \\
\hline
\end{tabular}

Nota: mês de maio de 2015 sem registro de impactos deflagrados por eventos pluviais; no ano de 2015 foi considerado o período entre janeiro e julho.

Fonte/Source: O Povo (2015); Diário do Nordeste (2015); Tribuna do Ceará (2015); O Estado (2015); FUNCEME (2015d).

e dois dias com chuvas de alta relevância. Foram sete dias com chuvas bem distribuídas e sete dias com chuvas generalizadas. Observaram-se quatro eventos extremos de chuva, todos na quadra chuvosa, nos meses de janeiro e março.

Os eventos pluviais extremos no ano de 2015 ocorreram nos dias 04 de janeiro e 09 de março. Em cada um desses dias, foram registrados dois eventos extremos de chuva. Nos demais houve equilíbrio entre a abrangência espacial das chuvas, classificadas como generalizadas e bem distribuídas.

O ano de 2015 apresentou déficit de $30,1 \%$ nos totais de precipitação na quadra chuvosa. As chuvas entre fevereiro e maio de 2015 apresentaram distribuição espacial irregular e ficaram abaixo da média histórica do período, contribuindo para ampliar a longa estiagem 
iniciada em 2012. A macrorregião do Litoral de Fortaleza apresentou o menor déficit de precipitação em 2015 $(-9,2 \%)$ (FUNCEME, 2015c).

De acordo com os resultados é possível afirmar que a distribuição espacial dos impactos das chuvas no território municipal apresenta-se predominante a partir do litoral nordeste ao noroeste, assim como toda a porção oeste até sudoeste. A porção centro-sul também apresenta uma concentração de bairros impactados. Tais locais historicamente apresentam impactos mais frequentemente, conforme também identificado por Barbosa e Zanella (2014) e Zanella e Olímpio (2017).

A porção centro-nordeste apresenta bairros de maior nível de renda média por domicílio e maior cobertura e qualidade das infraestruturas urbanas de drenagem, de saneamento básico e da rede viária, contudo, apresentam sérios problemas relacionados aos impactos das chuvas, sobretudo no Bairro Aldeota, onde predominam as interrupções parciais ou totais no trânsito de veículos, ocasionadas por alagamentos.

De uma forma geral, nos bairros mais bem assistidos por infraestruturas urbanas, os impactos produzidos pelas chuvas afetam principalmente a mobilidade urbana, em especial o transporte de passageiros. Mesmo com a melhor cobertura e qualidade da rede de drenagem urbana das águas pluviais a impermeabilização generalizada e os condutos subdimensionados contribuem para intensificação dos alagamentos, que naturalmente se desenvolvem em função das características geomorfológicas predominantes no sítio urbano da cidade, onde diversas lagoas localizadas nas feições dos tabuleiros pré-litorâneos e nas dunas fixas foram aterradas para o empreendimento urbano residencial e comercial mais adensado da cidade, assim como a canalização e supressão dos canais fluviais embutidos nas unidades geomorfológicas supracitadas.

$\mathrm{Na}$ maior parte da cidade, principalmente no cinturão periférico, a cobertura e a qualidade das infraestruturas urbanas de drenagem urbana e associadas à rede viária são inadequadas e insuficientes frente à dinâmica natural atuante na cidade, referente ao clima urbano e às repercussões hidrológicas e geomorfológicas, cujos eventos denotam um padrão morfodinâmico propício à produção de impactos na ocupação urbana, como também constatado por Zanella e Olímpio (2017).

Nesse contexto socioespacial o nível de afetação em relação aos impactos é maior em relação aos bairros mais abastados da cidade e os eventos naturais provocam danos generalizados, não somente nos aspectos físicos e funcionais relacionados à mobilidade urbana como também, e principalmente, no uso residencial, com sérios impactos na moradia da população de baixo nível médio da renda, que repercutem em danos humanos diversos, desde desabrigados até feridos e mortos.
A ocupação intensiva, adensada e indiscriminada de sistemas ambientais que apresentam forte morfodinâmica potencializada pelas chuvas, como encostas de dunas móveis e fixas, terraços marinhos e planícies flúviomarinhas na região natural da planície litorânea; planícies fluviais e lacustres e áreas de inundação sazonal em condições próximas às originais ou fortemente alteradas por intervenções construtivas indiscriminadas, principalmente por aterros; revela a inadequação da ocupação territorial urbana em relação à fragilidade dos sistemas ambientais existentes, constatação em consonância com o que foi identificado por Santos (2016) ao investigar o sítio urbano da cidade de Fortaleza. Esse é um dos principais fatores produtores dos impactos das chuvas nesses bairros da cidade.

A vulnerabilidade social presente no cinturão periférico da cidade, no entanto, é o principal fator responsável pela produção dos impactos dos eventos de chuva na cidade. Essa condição deriva da convergência de fatores representados pela localização desprivilegiada de grande parte da população, pela ocupação inadequada de ambientes naturais, cujos terrenos são menos valorizados pelo mercado imobiliário, pelo baixo padrão construtivo dos imóveis e pela cobertura inexistente ou insuficiente das infraestruturas urbanas em função da negligência histórica da gestão pública.

Pérez-Briceño et al. (2016), ao analisarem problemática semelhante nas cidades centro-americanas, corroboram com esse entendimento, ao afirmarem, de acordo com os resultados de seu estudo, que os impactos das chuvas nos centros urbanos investigados derivam necessariamente da integração entre fatores físiconaturais e socioeconômicos.

Considerando a expressão espacial da dinâmica natural as chuvas podem apresentar repercussões problemáticas aos diferentes bairros que formam os diferentes contextos sócioespaciais urbanos através de eventos naturais que demonstram forte morfodinâmica, entre eles os alagamentos, as inundações e deslizamentos, que podem ser deflagrados de forma isolada ou combinada. Com exceção das ressacas de mar, tipo de evento natural com menor recorrência e abrangência espacial, todos os outros tipos de eventos observados tem deflagração provocada pelas precipitações pluviais.

As inundações combinadas aos alagamentos tem a maior expressão em espacial entre os bairros da cidade. Desenvolvem-se preferencialmente ao longo das planícies fluviais e nas planícies lacustres. Esses sistemas ambientais estão intensivamente ocupados de forma inadequada e ilegal por diversos tipos de usos urbanos, mas principalmente pelo uso residencial promovido por população de baixa renda.

Os impactos das chuvas no uso residencial, principalmente observados nos bairros e comunidades mais pobres em 
relação ao nível de renda, servem também para evidenciar a formação de áreas de risco de desastres ambientais na cidade, onde predominam territórios produzidos por habitações extremamente precárias e com baixa capacidade de suporte frente à morfodinâmica atuante. Nessas áreas, a qualidade de vida é geralmente avaliada com muito baixa, com elevados índices de pobreza. As vulnerabilidades sociais múltiplas são agravadas pela fragilidade ambiental, tornando a situação insuportável, ampliando os problemas no período das chuvas mais intensas e extremas.

Serviços públicos e privados sofrem com as adversidades provocadas pelo baixo preparo da cidade em lidar com as chuvas. Atividades ligadas aos setores de saúde, educação, transportes em geral, até mesmo aeroviário, são afetados pelos impactos hidrometeóricos, produzindo grandes problemas no atendimento da população de mais baixa renda, que já se apresenta bastante precário.

A série temporal selecionada para análise dos impactos das chuvas representa uma amostra enfática exemplificadora de problemas históricos da cidade na sua relação sociedade e natureza, com acompanhamento e registro cotidiano dos problemas socioambientais mais graves. Mesmo compreendido dentro de um período de estiagem prolongada, registrado pela climatologia regional, os impactos das chuvas continuam recorrentes na cidade, principalmente durante o intervalo de meses entre dezembro e julho dos anos observados.

O tipo de análise realizada, que relaciona espacialmente a repercussão dos eventos de precipitação pluvial com os impactos provocados no território, se apresenta como importante meio para o desenvolvimento dos estudos técnicos e científicos dos riscos de desastres naturais em espaços urbanos. Favorece também o desenvolvimento de avaliações do comportamento dos sistemas ambientais integrando a dinâmica dos eventos naturais às formas de uso e ocupação da cidade. A compreensão da distribuição espacial dos problemas deflagrados pelos eventos naturais integrados é fundamental para o aprimoramento da geografia dos riscos ambientais. A partir dos resultados podese avançar na discussão dos caminhos possíveis do gerenciamento dos problemas supracitados.

A escala do estudo, em nível intraurbano, circunscrito nos limites político-administrativos do município, suscita uma abordagem intermediária dos estudos voltados ao planejamento ambiental entre o nível regional e o nível local dos bairros e comunidades, possibilitando a orientação das observações das manifestações do clima urbano em termos de impactos hidrometeóricos nas diversas porções da cidade, em função de suas características sócioespaciais e naturais integradas.

\section{Conclusão}

A avaliação dos impactos das chuvas na Cidade de Fortaleza no triênio 2013, 2014 e 2015 revelou que durante esse período foram registrados 30 dias com problemas noticiados. Os principais impactos hidrometeóricos na Cidade de Fortaleza decorreram de eventos naturais dinamizados pelas chuvas, provocando danos em residências e problemas generalizados no trânsito de veículos e pedestres (mobilidade urbana). Os problemas atingiram grande parte do território da cidade, nos mais heterogêneos contextos socioespaciais, precisamente 53 bairros, que representam $44,54 \%$ dos 119 bairros que compõem a cidade.

A avaliação dos impactos das chuvas, considerando o fator natural, demonstrou que não somente os eventos pluviais intensos (igual ou maior que $60 \mathrm{~mm}$ ) ou extremos (igual ou maior que $100 \mathrm{~mm}$ ) tem potencial de impactar o meio urbano. As chuvas de média relevância (iguais ou $>10 \mathrm{~mm}$ e $<60 \mathrm{~mm}$ ) foram as responsáveis pela deflagração de impactos hidrometeóricos na maioria absoluta dos dias com problemas registrados ( 24 dos 30 dias).

Os impactos das chuvas foram produzidos pela deflagração de eventos naturais como alagamentos, inundações, deslizamento de terra, além de ressacas do mar. Os problemas ambientais urbanos identificados apresentaram ampla distribuição espacial e generalização na desorganização na mobilidade urbana e danos em residências e estruturas construídas, assim como interrupção de serviços. A problemática pode ser correlacionada com as deficiências presentes na cidade em relação às infraestruturas e sistemas de saneamento e drenagem urbana, assim como a inadequação na ocupação dos ambientes naturais frágeis, com supressão de corpos hídricos e intensiva impermeabilização do solo, comprometendo a infiltração das águas das chuvas acelerando o escoamento superficial e o transbordamento dos corpos hídricos.

Destaca-se a necessidade de investimentos em planejamento e execução de programas e projetos de infraestruturas urbanas adequadas. O reordenamento territorial do uso e ocupação do sítio natural urbano é fundamental para resolução dos problemas ambientais urbanos evidenciados, assim como medidas de prevenção aos efeitos de eventos naturais extremos, tendo em vista que apresentam elevado potencial de produzir desastres ambientais na Cidade de Fortaleza.

\section{Referências bibliográficas}

Brandão, Ana Maria de Paiva Macedo (2001). Clima urbano e enchentes na Cidade do Rio de Janeiro. In: Guerra, Antônio José Teixeira; Cunha, Sandra Baptista da. (ORG) - Impactos ambientais urbanos no Brasil. Bertrand Brasil, Rio de Janeiro, 47-109p. 
Brasil (2013). Atlas do censo demográfico 2010 / IBGE. - Rio de Janeiro: IBGE. 160 p. Disponível: http:// censo2010.ibge.gov.br/apps/atlas/. [29/04/2016].

Chandler, T. J. (1976). Urban climatology and its relevance to urban design. Technical Note 149. Geneva, World Meteorological Organization.

DIÁRIO DO NORDESTE (2015). Acervo de reportagens. Disponível: www.diariodonordeste.com.br. [30/07/2015]

Ferreira, Antônio Geraldo; Mello, Namir Giovanni da Silva (2005). Principais sistemas atmosféricos atuantes sobre a Região Nordeste do Brasil e a influência dos oceanos Pacífico e Atlântico no clima da região. Revista Brasileira de Climatologia, n. 1, v.1, 15-28p.

FUNCEME (2015)a. Quadra chuvosa 2013 no Ceará fica 37,7\% abaixo da média. Disponível: http://www. funceme.br/index.php/comunicacao/noticias/507quadra-chuvosa-2013-no-cear\%C3\%A1-fica-37,7abaixo-da-m\%C3\%A9dia. [01/09/2015].

FUNCEME (2015)b. Chuvas na quadra chuvosa de 2014 ficaram 24\% abaixo da média. Disponível: http:// www. funceme.br/index.php/comunicacao/ noticias / 604-chuvas-na-quadra-chuvosa-de-2014ficaram-24-abaixo-da-m\%C3\%A9dia. [01/09/2015].

FUNCEME (2015)c. Em 2015, Ceará teve déficit de 30,1\% nas chuvas entre fevereiro e maio. Disponível: http: / /www. funceme.br/index.php/comunicacao/noticias/667. em-2015,-cear\%C3\%A1-teve-d\%C3\%A9ficit-de-30,1-naschuvas-entre-fevereiro-e-maio. [01/09/2015].

FUNCEME (2015)d. Banco de dados meteorológicos. Disponível: www. funceme.br. [01/09/2015].

Goodin, D.; Brazel, T.; Fountain, A.; Hadley, J.; Juday, G.; Kloeppel, B.; Knapp, A.; Losleben, M.; Smith, M. (2004). LTER Extreme events working group. In: Workshop Help Annals, Portland.

Landsberg, H. E. (1981). The urban climate. New York: Academic Press.

Magalhães, Gledson Bezerra; Zanella, Maria Elisa (2011). Comportamento climático da Região Metropolitana de Fortaleza. Mercator, Fortaleza, v.10, n.23, set./ dez. 2011, p.129-145.

Mendonça, Francisco (2011). Riscos, vulnerabilidades e resiliência socioambientais urbanas. Inovações na análise geográfica. Revista da ANPEGE, v.7, n.1, número especial, p.111-118.

Monteiro, Carlos Augusto de Figueiredo (1976). Teoria e Clima Urbano (tese de doutorado). Instituto de Geografia da USP, São Paulo, 181p.

Monteiro, Carlos Augusto de Figueiredo (1990). Cidade como processo derivador ambiental e a geração de um clima urbano: estratégias na abordagem geográfica. Revista GEOSUL. N.9, ano V, semestre 1. P.80-114.

Monteiro, Carlos Augusto de Figueiredo (2011). Teoria e clima urbano. In: Mendonça, Francisco; Monteiro, Carlos Augusto de Figueiredo. (Org.) - Clima urbano. Contexto. São Paulo. (1 $1^{\mathrm{a}}$ edição, $2^{\mathrm{a}}$ reimpressão); 9-65p.

Monteiro, Jander Barbosa; Zanella, Maria Elisa (2013). Eventos extremos diários em Fortaleza-CE, Brasil: Uma análise estatística de episódios pluviométricos intensos. Anales del XIV Encuentro de Geógrafos de América Latina, $14^{\circ}$ Encontro de Geógrafos da América Latina, Lima, Peru.

Monteiro, Jander Barbosa; Zanella, Maria Elisa (2014). Eventos pluviométricos extremos e impactos associados em Fortaleza: CE: uma análise a partir da técnica de quantis. Silva, Charlei Aparecido; Fialho, Edson Soares; Steinke, Ercília Torres. (Org.). Experimentos em Climatologia Geográfica. 1 ${ }^{\mathrm{a}}$. Ed. Dourados: Editora da UFGD. V. 1. 391p. P. 165-186.

O ESTADO (2015). Acervo de reportagens. Disponível: www.oestado.com.br. [30/07/2015].

O POVO (2015). Acervo de reportagens. Disponível: www.opovo.com.br. [30/07/2015].

Oke, T.R. (1984). Methods in Urban Climatology. In: Kirschofer, W.; Ohmura, A.; Wanner, H. (Editors). Applied Climatology. Zurcher Geog. Schriften, n`14, pp.19-29.

Olímpio, João Luís Sampaio; Vieira, Patrícia Mena Barreto; Zanella, Marial Elisa; Sales, Marta Celina Linhares (2013). Episódios pluviais extremos e a vulnerabilidade socioambiental do Município de Fortaleza: o evento do dia 27/03/2012. GEO UERJ, ano $15, \mathrm{v} .1,1^{\circ}$ semestre, p.181-206.

Pérez-Briceño, Paula M.; Alfaro; Eric J.; Hidalgo, Hugo G.; Jiménez, Francisco (2016). Distribución espacial de impactos de eventos hidrometeorológicos en América Central. Revista de Climatología, n.16, P.63-75.

Santos, Jader de Oliveira (2011). Fragilidade e riscos socioambientais em Fortaleza-CE: contribuições ao ordenamento territorial (Doutorado em Geografia). Faculdade de Filosofia, Letras e Ciências Humanas (FFLCH), Programa de Pós-Graduação em Geografia Física. Universidade de São Paulo, São Paulo, 331p.

Santos, Jader de Oliveira (2015). Relações entre fragilidade ambiental e vulnerabilidade social na susceptibilidade aos riscos. Mercator, Fortaleza, v. 14, n. 2, mai./ago, p. 75-90.

Santos, Jader de Oliveira (2016). Fragilidade e riscos socioambientais em Fortaleza-CE. $1^{\text {a }}$ edição. Fortaleza: Imprensa Universitária. V.1. 188p. 
Santos, Jader de Oliveira; Ross, Jurandyr Luciano Sanches (2012). Fragilidade ambiental urbana. Revista da ANPEGE, v.8, n.10, ago-dez, p.127-144.

Souza, Marcos José Nogueira de (2009). Diagnóstico geoambiental do Município de Fortaleza: subsídio ao macrozoneamento ambiental e à revisão do plano diretor participativo - PDPFor. Fortaleza, Prefeitura Municipal de Fortaleza, 174p. Fortaleza. (1 ${ }^{a}$. Edição).

Taesler, Roger (1986). Urban Climatological Methods and Data. In Oke, T.R. (Editor). Urban Climatology and its Applications with Special Regard to Tropical Areas. Geneva, World Meteorological Organization. pp.200-236.

TRIBUNADO CEARÁ (2015). Acervo de reportagens. Disponível: www.tribunadoceara.com.br. [30/07/2015].
Wisner, Bem; Blaikie, Piers; Cannon, Terry; Davis, lan (2003). At risk: natural hazards, people's vulnerability and disasters. Second Edition. London: Routledge. 124p.

Zanella, Maria Elisa; Sales, Marta Celina Linhares; Abreu, Nair Júlia Andrade (2009). Análise das precipitações diárias intensas e impactos gerados em Fortaleza, CE. GEOUSP - Espaço e Tempo, n.25, P.53-68.

Zanella, Maria Elisa; Olímpio, João Luís Sampaio (2017). Impactos pluviais, risco e vulnerabilidades em Fortaleza-CE. In: Mendonça, Francisco A. (Org). Riscos Climáticos: vulnerabilidades e resiliências associadas. Edição em versão digital. Jundiaí: Paco Editorial. 